\title{
TRPM3 channel stimulated by pregnenolone sulphate in synovial fibroblasts and negatively coupled to hyaluronan
}

\author{
Coziana Ciurtin ${ }^{+1}$, , Yasser Majeed ${ }^{+1}$, Jacqueline Naylor ${ }^{1}$, Piruthivi Sukumar ${ }^{1}$, Anne A English³, Paul Emery ${ }^{3}$ and \\ David J Beech*1
}

\begin{abstract}
Background: Calcium-permeable channels are known to have roles in many mammalian cell types but the expression and contribution of such ion channels in synovial cells is mostly unknown. The objective of this study was to investigate the potential relevance of Transient Receptor Potential Melastatin 3 (TRPM3) channel to fibroblast-like synoviocytes (FLSs) of patients with rheumatoid arthritis.

Methods: The study used RT-PCR and immunofluorescence to detect mRNA and protein. Intracellular calcium measurement detected channel activity in a FLS cell-line and primary cultures of FLSs from patients with rheumatoid arthritis. Enzyme-linked immunosorbent assays measured hyaluronan.

Results: Endogenous expression of TRPM3 was detected. Previously reported stimulators of TRPM3 sphingosine and pregnenolone sulphate evoked sustained elevation of intracellular calcium in FLSs. The FLS cell-line showed an initial transient response to sphingosine which may be explained by TRPV4 channels but was not observed in FLSs from patients. Blocking antibody targeted to TRPM3 inhibited sustained sphingosine and pregnenolone sulphate responses. Secretion of hyaluronan, which contributes adversely in rheumatoid arthritis, was suppressed by pregnenolone sulphate in FLSs from patients and the effect was blocked by anti-TRPM3 antibody.
\end{abstract}

Conclusions: The data suggest that FLSs of patients with rheumatoid arthritis express TRPM3-containing ion channels that couple negatively to hyaluronan secretion and can be stimulated by pharmacological concentrations of pregnenolone sulphate.

\section{Background}

Transient Receptor Potential (TRP) was discovered in Drosophila melanogaster as a component of the visual response to bright light. Subsequently, 28 related genes were discovered in mammals, found to be widely expressed and shown to be involved in various chemical and temperature sensing mechanisms [1,2]. The mammalian TRP channels are divided into subgroups according to amino acid sequence similarities; one subgroup is the $\mathrm{M}$ (melastatin) subgroup of which there are eight members, while other subgroups include the $\mathrm{V}$ (vanilloid) and $\mathrm{C}$ (canonical) subgroups. We previously reported on

\footnotetext{
* Correspondence: d.j.beech@leeds.ac.uk

1 Institute of Membrane \& Systems Biology, Faculty of Biological Sciences,

University of Leeds, Leeds, LS2 9JT, UK

+ Contributed equally

Full list of author information is available at the end of the article
}

expression and function of TRPC channels in fibroblastlike synoviocytes (FLSs) [3]. There have also been indications of TRPV1, TRPV4 and TRPM8 functions in FLSs $[4,5]$, but regulation and importance of TRP channels in the synovial lining is relatively unknown. Here we focus on TRPM3 [6-11]. When over-expressed in cell-lines TRPM3 forms $\mathrm{Ca}^{2+}$-permeable non-selective cationic channels at the plasma membrane that can be stimulated by factors including sphingosine and pregnenolone $[8,10]$. Activity of endogenous TRPM3 channels and the biological functions of such channels are poorly understood but a recent seminal study showed expression in pancreatic $\beta$-cells and suggested coupling of pregnenolone to insulin secretion via TRPM3 [10]. Pregnenolone is derived from cholesterol and the precursor for steroid hormones including the corticosteroids, 
androgens, oestrogen and progesterone. It is sulphated in vivo and the sulphated form (pregnenolone sulphate) is suggested to have biological actions, including through glutamate and $\gamma$-aminobutyric acid receptors of neurones $[12,13]$.

Rheumatoid arthritis (RA) is a common and debilitating disease affecting large numbers of people world-wide. Inflammation of the synovial lining is a striking feature of the disease and is contributed to strongly by hyperplasia of FLSs [14-16]. Hyaluronan is secreted by FLSs and is a well-recognised lubricant of physiological joints, but excess hyaluronan from FLSs and degradation products of hyaluronan contribute to RA [17]. Furthermore, hyaluronan from other cell types may have general adverse consequences in inflammatory conditions, including in atherosclerosis $[18,19]$.

In this study we investigated TRPM3 and its stimulators by using a model FLS cell-line and primary cultures of FLSs from patients diagnosed with RA.

\section{Methods}

HIG-82 cells

HIG-82 cells are a fibroblast-like synoviocyte (FLS) cellline from soft tissue lining the knee joints of rabbits [20,3]. Cells were cultured in Ham's F-12 medium (Gibco, UK) containing $10 \%$ fetal calf serum, 100 units. $\mathrm{ml}^{-1}$ penicillin and $100 \mu \mathrm{g} \cdot \mathrm{ml}^{-1}$ streptomycin. Cells were maintained in a humidified atmosphere of 5\% CO2 in air and re-plated on 96-well plates $24 \mathrm{hr}$ prior to experiments. The cells stained positively for CD55 and negatively for CD68, supporting their identification as FLS-like cells [3].

\section{Synovial tissue}

Tissue biopsies were obtained during arthroscopy from the synovial lining of knee joints of patients diagnosed with RA at the Academic Unit of Musculoskeletal Disease, Chapel Allerton Hospital, Leeds. Ethical approval was given by the Local Ethics Committee. Patient informed consent was obtained. No attempt was made to correlate findings with the severity of the RA or other patient characteristics. Patient therapy was standard disease-modifying anti-rheumatic drugs but not anti-tumor necrosis factor (TNF) therapies or high-dose steroids.

\section{Primary cultures of FLSs}

Synovial biopsies were washed with phosphate-buffered saline and digested with $0.25 \%$ type $1 \mathrm{~A}$ collagenase (Stem Cell Technologies, UK) for $4 \mathrm{hr}$ at $37^{\circ} \mathrm{C}$ and FLSs were then cultured in DMEM/F-12 + Glutamax (Gibco, UK) containing $10 \%$ fetal calf serum, 100 units. $\mathrm{ml}^{-1}$ penicillin and $100 \mu \mathrm{g} \cdot \mathrm{ml}^{-1}$ streptomycin. FLSs were maintained in a humidified atmosphere of $5 \% \mathrm{CO}_{2}$ in air and replated on multi-well plates prior to experiments.

\section{Over-expression of TRPV4}

Chinese hamster ovary (CHO) K1 cells stably expressing human TRPV4 were maintained in Ham's F12 (Gibco, $\mathrm{UK}$ ) in the presence of $1 \mathrm{mg} \mathrm{ml}^{-1} \mathrm{G} 418$ (Sigma, UK).

\section{RT-PCR}

Total RNA was extracted using a Tri-reagent protocol followed by DNase I (Ambion) treatment. $1 \mu \mathrm{g}$ of total RNA was used for reverse transcription (RT) based on oligodT primers and AMV RT enzyme. TRPM3 PCR primers were (5'-3') AGCAGTTCTACCTAACGT (forward primer) and CTTGCTCGACTAGACTTG (reverse primer). The expected product size was $268 \mathrm{bp}$. The specificity of the RT-PCR was verified by reactions without RT (-RT) and by sequencing of the PCR product (University of Leeds, UK).

\section{Labeling with antibody}

Tissue sections ( $4 \mu \mathrm{m}$ thick) were cut from snap-frozen biopsy samples, fixed with acetone and stored at $-80^{\circ} \mathrm{C}$ until use (immunofluorescence labeling) or fixed with $1 \%$ paraformaldehyde (immunohistochemistry). Staining was according to standard protocols: Briefly, sections were incubated with primary antibody over night at $4{ }^{\circ} \mathrm{C}$ and secondary antibody (goat anti-rabbit IgG-FITC or HRP) for $1 \mathrm{hr}$ at room temperature. Slides were mounted (Vector Labs, UK) and imaged with a confocal or brightfield microscope. Anti TRPM3 (TM3E3) and anti-CD55 (clone 67, Serotec) primary antibodies were used at 1:500 and 1:200 dilutions respectively. TM3E3 was described previously [11].

\section{Hyaluronan secretion}

Primary FLSs were cultured in 6 well plates for $24 \mathrm{hr}$ without serum starvation and then fresh medium was added containing PregS, dexamethasone, TNF or vehicle. Incubations with antibodies occurred in culture medium for $2 \mathrm{hr}$ prior to addition of compounds. Supernatants were collected after $24 \mathrm{hr}$, frozen and analysed using an enzyme-linked immunosorbent assay (ELISA) that detects hyaluronan (HA ELISA kit, Corgenix).

\section{Intracellular $\mathrm{Ca}^{2+}$ measurement}

$\mathrm{Ca}^{2+}$ was measured using a FlexStation II controlled by SoftMax Pro 4.7.1 software (Molecular Devices, USA). Cells were plated at $60-70 \%$ confluence on 96-well square-bottomed clear plates (Nunclon, UK) $24 \mathrm{hr}$ before experiments. Immediately prior to recording, cells were incubated for $1 \mathrm{hr}$ at $37^{\circ} \mathrm{C}$ in SBS (see below) containing $10 \mu \mathrm{M}$ fura-2 acetoxymethyl ester and then washed with SBS 2-3 times before adding fresh SBS. Incubations with TM3E3 antibody occurred for $2 \mathrm{hr}$ prior to the incubation with the fluorescent dye, during the incubation and the washing period (i.e. for $3.5 \mathrm{hr}$ prior to recording data). Excess TM3E3 was removed immediately prior to experi- 
ments. Excitation light alternated between 340 and 380 $\mathrm{nm}$, while emission was filtered at $510 \mathrm{~nm}$. Experiments were at room temperature $\left(21 \pm 3^{\circ} \mathrm{C}\right)$. Standard bath solution (SBS) contained (mM): $130 \mathrm{NaCl}, 5 \mathrm{KCl}, 1.2 \mathrm{MgCl}_{2}$, $1.5 \mathrm{CaCl}_{2}, 8$ glucose and 10 Hepes (titrated to $\mathrm{pH} 7.4$ using $\mathrm{NaOH}$ and adjusted to 290 mOsm using mannitol). $\mathrm{Ca}^{2+}$-free SBS was SBS in which $\mathrm{CaCl}_{2}$ was replaced by 0.4 mM EGTA.

\section{Reagents}

All reagents were from Sigma (UK) or BDH (British Drug House, Poole, UK). Sphingosine was prepared as a $20 \mathrm{mM}$ stock in $100 \%$ ethanol and stored at $-20^{\circ} \mathrm{C}$, pregnenolone sulphate as a $100 \mathrm{mM}$ stock in DMSO and stored at $4{ }^{\circ} \mathrm{C}$. ATP was prepared as a $100 \mathrm{mM}$ stock in $\mathrm{H}_{2} \mathrm{O}$ and lysophosphatidylcholine (LPC) was a $100 \mathrm{mM}$ stock in $100 \%$ methanol; both were stored at $-20^{\circ} \mathrm{C}$.

\section{Data analysis}

Data are expressed as mean \pm s.e.m. and paired data sets compared using two-tailed $t$-tests. For FlexStation recordings, the numbers of experiments are indicated as $\mathrm{N} / \mathrm{n}$, where $\mathrm{N}$ is the number of wells used in the 96 -well plate and $\mathrm{n}$ is the number of independent experiments (i.e. different 96-well plates and batches of cells). All data from primary cultures of FLSs derived from at least 3 independent patient samples. Statistical significance is indicated by probability (P-value) of "P $<0.05$ unless specified; NS indicates no significant differences. Data were handled, analysed and prepared for presentation using Origin software (Origin Lab Corporation, Northampton, CA, USA).

\section{Results}

\section{Endogenous expression of TRPM3}

Messenger RNA encoding TRPM3 was detected in FLSs from patients with RA (Fig 1a). The TRPM3 protein was expressed endogenously because anti-TRPM3 antibody [11] labeled cells at the edge of the synovial lining in synovial biopsies (Fig 1b); the cells were CD55 positive (data not shown), supporting identification as FLSs [3]. TRPM3 could also be detected in the sub-lining cell layer and in blood vessels of the joint (Fig 1c).

\section{$\mathrm{Ca}^{2+-e n t r y ~ e v o k e d ~ b y ~ s p h i n g o s i n e ~ i n ~ H I G-82 ~ c e l l s ~}$}

Because of limited supply of synovial biopsies we first sought to investigate the functional relevance of TRPM3 expression through experiments on a FLS cell-line (HIG82 cells), a proposed model system of proliferating FLSs in joints. As with synovial biopsies, there was labeling of the cells by anti-TRPM3 (data not shown) and anti-CD55 antibodies [3].

TRPM3 channels are suggested to be $\mathrm{Ca}^{2+}$ permeable and so we studied channel activity using an intracellular

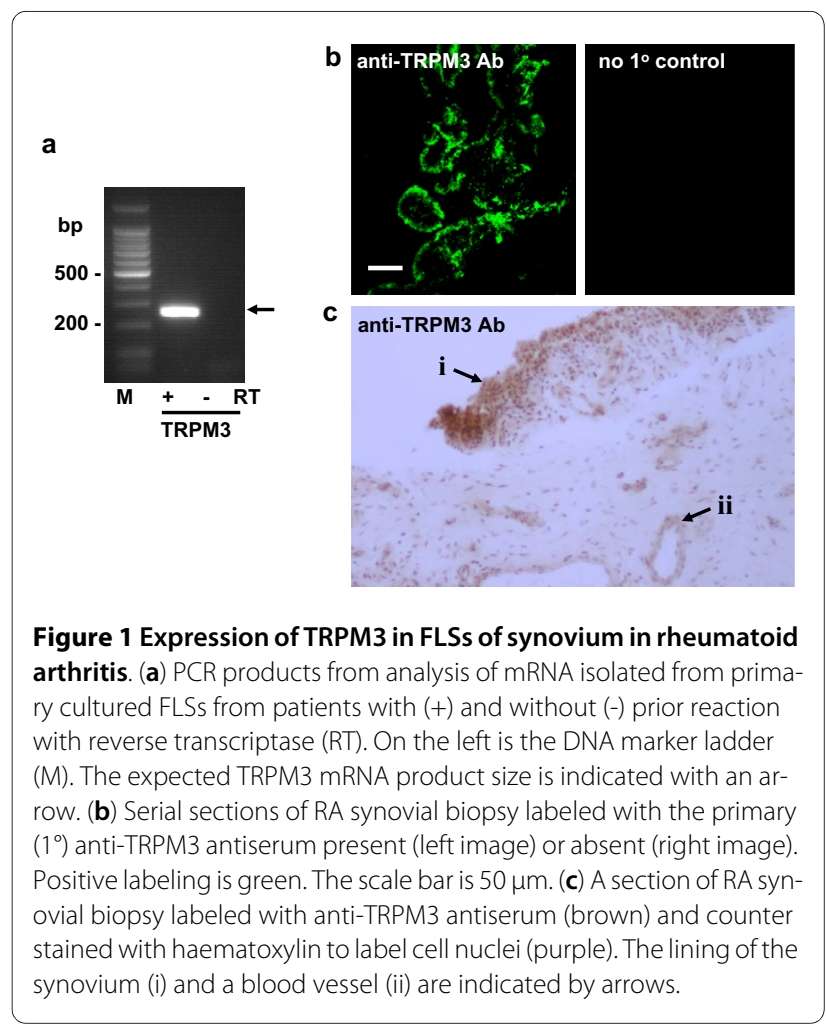

$\mathrm{Ca}^{2+}$ indicator. Cells were exposed to sphingosine because it has been suggested to stimulate human TRPM3 overexpressed in HEK 293 cells [8]. In HIG-82 cells, sphingosine elicited a rise in the intracellular $\mathrm{Ca}^{2+}$ concentration in two phases - an initial transient phase followed by a sustained phase (Fig 2a). Dimethylsphingosine also stimulated over-expressed human TRPM3 [8] and elicited transient followed by sustained $\mathrm{Ca}^{2+}$ responses in HIG-82 cells (Fig 2b).

The transient and sustained phases of the sphingosine and dimethylsphingosine responses depended on the presence of extracellular $\mathrm{Ca}^{2+}(\mathrm{Fig} 2 \mathrm{a}, \mathrm{b})$, which suggested that both phases were due to $\mathrm{Ca}^{2+}$-influx. It was conceivable however that removal of extracellular $\mathrm{Ca}^{2+}$ caused depletion of intracellular $\mathrm{Ca}^{2+}$ stores, leading to the false impression of $\mathrm{Ca}^{2+}$-influx. To investigate this possibility we applied extracellular ATP to activate G protein-coupled purinoceptors. ATP elicited a predominantly transient rise in $\mathrm{Ca}^{2+}$ that was unaffected by removal of extracellular $\mathrm{Ca}^{2+}$ (Fig 2c), showing that ATP acted by evoking $\mathrm{Ca}^{2+}$-release and that $\mathrm{Ca}^{2+}$-stores had not been inadvertently depleted. The data support the conclusion that sphingosine evoked $\mathrm{Ca}^{2+}$ influx.

\section{Role of TRPM3 in the sustained sphingosine response of HIG-82 cells}

It was previously described that the anti-TRPM3 antibody TM3E3 has an inhibitory effect on human TRPM3 

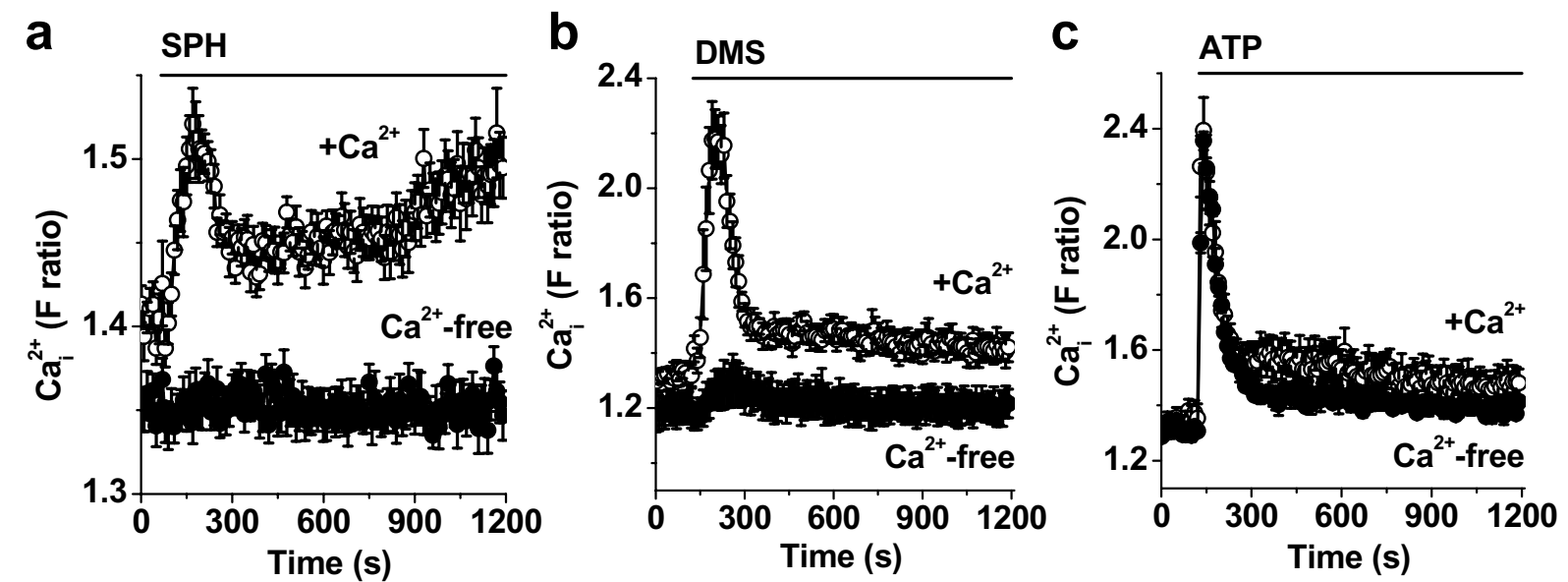

Figure 2 Sphingosine-evoked $\mathrm{Ca}^{2+}$ signals in HIG-82 cells. Data were generated by intracellular $\mathrm{Ca}^{2+}$ measurement. Responses elicited by (a) sphingosine (SPH, $20 \mu \mathrm{M})$, (b) dimethylsphingosine (DMS, $20 \mu \mathrm{M})$ or (c) adenosine triphosphate (ATP, $100 \mu \mathrm{M}$ ) were tested in either $1.5 \mathrm{mM}$ Ca2+-containing $\left(+\mathrm{Ca}^{2+}\right)$ or $\mathrm{Ca}^{2+}$-free extracellular solution. Responses are each representative of $3(n)$ independent experiments.

over-expressed in HEK 293 cells [11]. We, therefore, investigated the effect of TM3E3 on the sphingosine response in HIG-82 cells. The sustained response to sphingosine was clearly suppressed (Fig 3a, b). The transient response to sphingosine was either unaffected (Fig 3a) or slightly potentiated, with the mean data just reaching statistical significance (Fig 3b). Evidence for specificity of TM3E3 came from its lack of effect on the $\mathrm{Ca}^{2+}$ response evoked by the $\mathrm{Ca}^{2+}$-ATPase inhibitor thapsigargin (Fig 3c, and see below). The data suggest that a substantial component of the sustained response to sphingosine was due to stimulation of TRPM3-containing $\mathrm{Ca}^{2+}$-influx channels.

\section{Potential role of TRPV channels in the transient sphingosine response of HIG-82 cells}

To gain insight into the TRPM3-independent transient response we investigated its sensitivity to ruthenium red, which is a non-specific inhibitor of TRP channels [1]. Ruthenium red was inhibitory (Fig 3d), consistent with the transient response being substantially due to $\mathrm{Ca}^{2+}$ influx and suggesting dependence on TRP channels [1]. Ruthenium red is best known as an inhibitor of the TRPV subfamily of TRP channels. Therefore, we applied TRPV channel stimulators in an effort to mimic the transient effect of sphingosine.

$4 \alpha$-Phorbol 12,13-didecanoate (4- $\alpha$-PDD) is an agonist at TRPV4 channels and appears to be specific for this channel type [21]. The compound elicited a $\mathrm{Ca}^{2+}$ response (Fig 3e), which suggested that functional TRPV4 channels were expressed in the HIG-82 cells. Removal of extracellular $\mathrm{Ca}^{2+}$ reduced the sustained response to 4- $\alpha-\mathrm{PDD}$, although a transient response remained (Fig 3e). The data suggest that TRPV4 channels are functional at the plasma membrane. Consistent with the notion that sphingosine caused transient $\mathrm{Ca}^{2+}$ entry in HIG-82 cells because it stimulated TRPV4, sphingosine evoked a similar transient rise of the intracellular $\mathrm{Ca}^{2+}$ concentration in a cell-line stably expressing the clone of human TRPV4 (Fig 3f).

\section{Effect of sphingosine on primary FLSs}

Sphingosine responses were also investigated in primary cultures of FLSs from patients with RA to determine the relevance of the HIG-82 cell data. As with HIG-82 cells, sphingosine elicited sustained $\mathrm{Ca}^{2+}$ responses that depended on extracellular $\mathrm{Ca}^{2+}$ (Fig 4a). In contrast to HIG-82 cells, there was no transient response to sphingosine (Fig 4a). Consistent with dominant contribution of sustained $\mathrm{Ca}^{2+}$ entry and TRPM3 channels, TM3E3 antibody inhibited the response (Fig 4b). TM3E3 did not act non-specifically because it had no effect on $\mathrm{Ca}^{2+}$ responses to ATP or lysophosphatidylcholine (LPC) (Fig $4 c, d)$.

\section{Effect of pregnenolone sulphate on primary FLSs}

A recently-reported stimulator of TRPM3 channels is pregnenolone sulphate [10]. Pregnenolone sulphate elicited a robust rise in $\mathrm{Ca}^{2+}$ in FLSs from patients with RA (Fig 5a). The response was abolished in the absence of extracellular $\mathrm{Ca}^{2+}$ (Fig 5a) and the response to sphingosine was not additive on top of the pregnenolone sulphate response (Fig 5b), suggesting that pregnenolone sulphate and sphingosine stimulate the same $\mathrm{Ca}^{2+}$ influx pathway. In support of this hypothesis, TM3E3 antibody strongly inhibited the pregnenolone sulphate response 


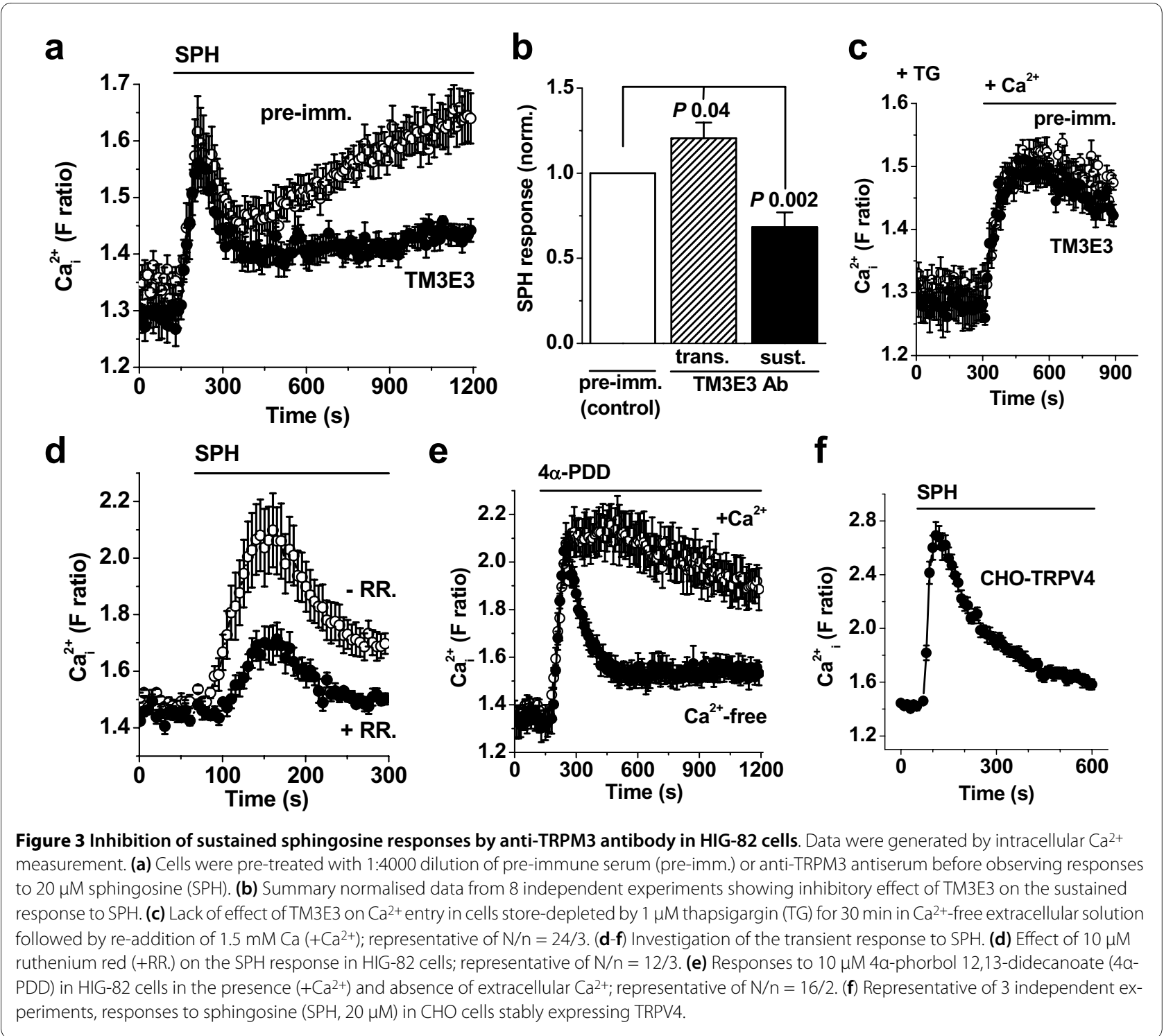

(Fig 5c). Concentration-response curves were constructed to determine if the effect of pregnenolone sulphate on $\mathrm{Ca}^{2+}$-influx might be relevant to physiological concentrations of the steroid. Concentrations of $>1 \mu \mathrm{M}$ pregnenolone sulphate were effective at elevating the intracellular $\mathrm{Ca}^{2+}$ concentration (Fig $5 \mathrm{~d}$ ), which are above the known physiological concentrations of this steroid $[22,23]$.

\section{Functional roles of TRPM3 and pregnenolone sulphate responses in primary FLSs}

Hyaluronan is secreted by FLSs and its secretion is excessive and pro-inflammatory in RA [17]. We hypothesized that $\mathrm{Ca}^{2+}$ might modulate the secretion. Hyaluronan secretion was, therefore, measured and first investigated using the established positive controls tumour necrosis factor and dexamethasone that stimulate and inhibit hyaluronan secretion respectively; both compounds acted as expected (Fig 6a). Like dexamethasone, pregnenolone sulphate inhibited hyaluronan secretion (Fig 6a). TM3E3 alone had no effect (Fig 6b) but prevented the action of pregnenolone sulphate (Fig 6c). TM3E3 was ineffective when it had been preadsorbed to its antigenic peptide (Fig 6c), showing that its effect depended on the TRPM3 peptide recognition site of the antibody. Although dexamethasone also inhibited hyaluronan secretion (Fig 6a), its effect was unchanged by TM3E3 (Fig 6d). The data suggest that stimulation of TRPM3 inhibited hyaluronan production or secretion.

\section{Discussion}

The data add to an emerging picture of multiple types of TRP channel in fibroblast-like synoviocytes (FLSs) [3,4], specifically suggesting that TRPM3 channels enable sus- 


\section{a}

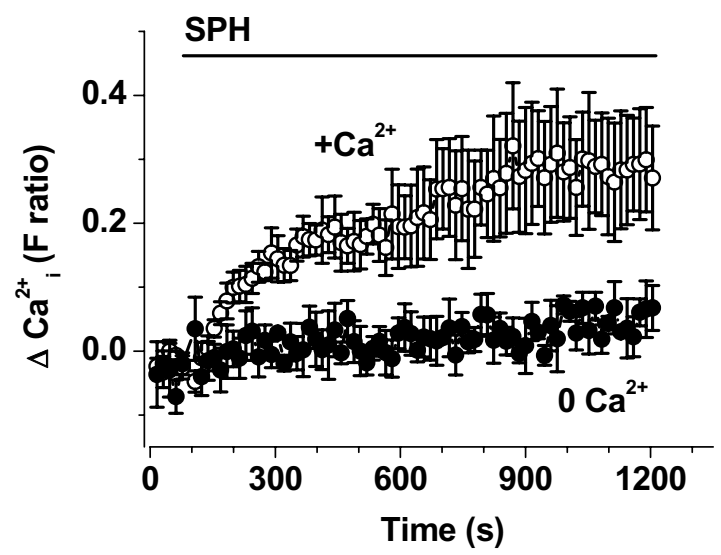

C

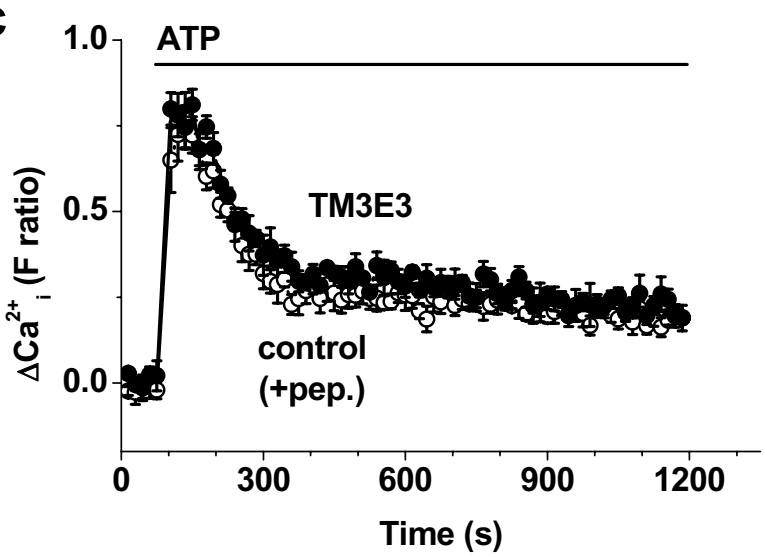

b
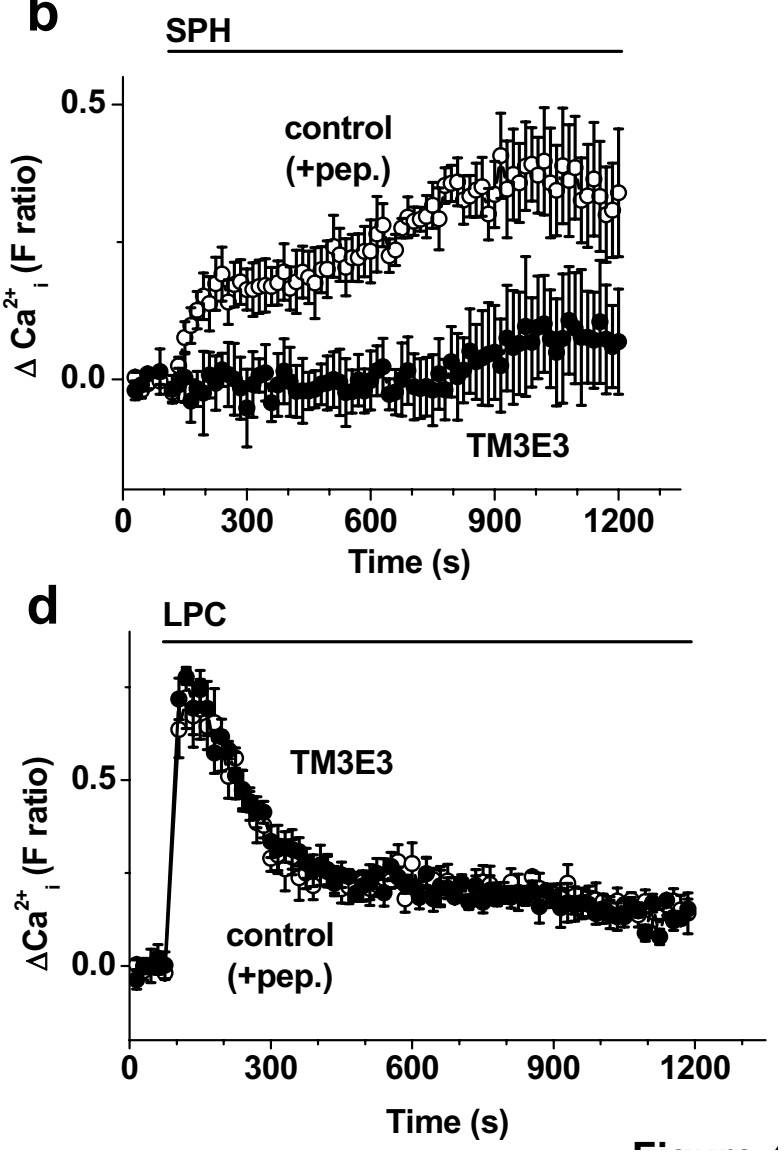

Figure $4 \mathrm{Ca}^{2+}$-entry evoked by sphingosine (SPH) in primary cultures of FLSs from patients with RA. (a) Intracellular $\mathrm{Ca}^{2+}$ measurement showing the effect of external application of $20 \mu \mathrm{M} \mathrm{SPH}$ in the presence and absence of extracellular $\mathrm{Ca}^{2+}$. (b-d) Intracellular $\mathrm{Ca}^{2+}$ measurements showing responses to externally applied substances: (b) $20 \mu \mathrm{M} \mathrm{SPH}$, (c) $100 \mu \mathrm{M}$ adenosine triphosphate (ATP), and (d) $30 \mu \mathrm{M}$ lysophosphatidylcholine (LPC). In paired experiments on the same 96-well plate, responses were compared after pre-treatment with anti-TRPM3 antibody (TM3E3) or TM3E3 preadsorbed to its antigenic peptide ("+pep."; control group). (a-d) All data points are $\mathrm{N}=8$ and representative of 3 ( $\mathrm{n}$ ) independent experiments.

tained $\mathrm{Ca}^{2+}$ responses to sphingosine and pregnenolone sulphate. Of potential functional relevance was the observation that pregnenolone sulphate acted via TRPM3 to negatively modulate hyaluronan secretion, independently of the pathway activated by glucocorticoids. The data, therefore, suggest a molecular basis for therapeutic benefit of pregnenolone in rheumatoid arthritis, as initially suggested in publications of the 1950s and commonly suggested in the contemporary field of dietary supplementation.

We cannot exclude that endogenous concentrations of pregnenolone sulphate (or a related steroid) become sufficiently high in RA to stimulate TRPM3 in FLSs but there is currently no evidence to support such a hypothesis. Small effects of the related steroids pregnenolone, dehydroepiandrosterone (DHEA) and DHEA sulphate (DHEA-S) were observed, but again the concentrations are unlikely to be physiologically relevant. Physiological DHEA-S concentrations are high (3-4 $\mu \mathrm{M}$ in patients with
RA [24]) but we observed only minor effects of $100 \mu \mathrm{M}$ DHEA-S on $\mathrm{Ca}^{2+}$ in primary cultures of FLSs and no effects of lower concentrations (C Ciurtin et al, unpublished data).

There is greater reason to suggest that the effect of pregnenolone sulphate on $\mathrm{Ca}^{2+}$ entry in FLSs is pharmacologically interesting because pregnenolone (much of which is sulphated in vivo) is self-administered as a dietary supplement and informally considered to have general health-giving benefits, including in RA. There are on-going clinical trials of pregnenolone or related steroids to rigorously test the benefits and adverse effects, but not yet in RA. Reasons why pregnenolone might be considered are as follows: (i) a range of small-scale studies published in the early 1950s suggest that pregnenolone may be of benefit in RA (Additional file 1); (ii) our data suggest a mechanistic basis for a beneficial action of pregnenolone in RA (i.e. inhibition of hyaluronan secretion via TRPM3 stimulation); (iii) Pregnenolone has been 

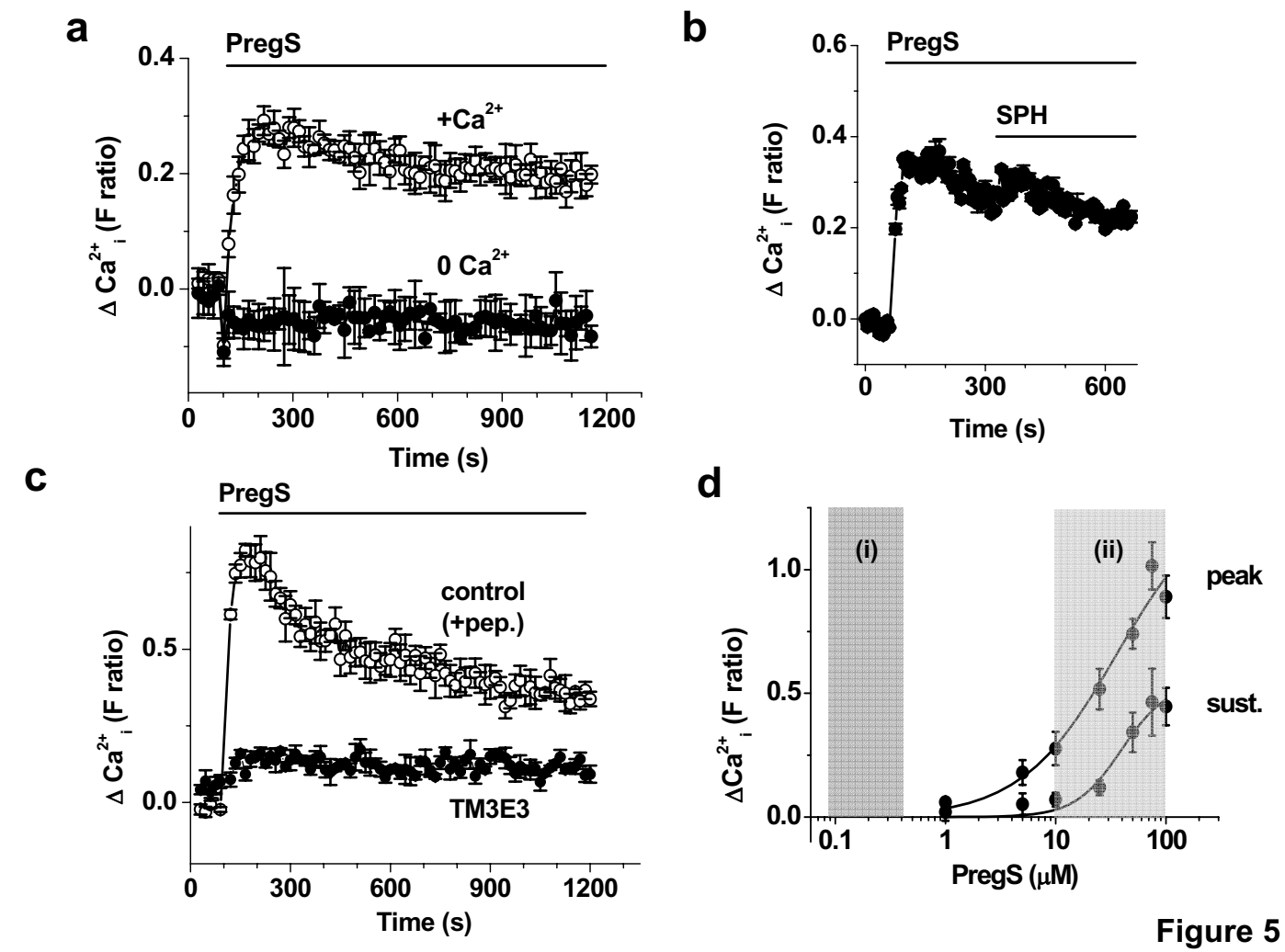

Figure 5

Figure $5 \mathrm{Ca}^{2+-e n t r y ~ e v o k e d ~ b y ~ p r e g n e n o l o n e ~ s u l p h a t e ~(P r e g S) ~ i n ~ p r i m a r y ~ c u l t u r e s ~ o f ~ F L S s ~ f r o m ~ p a t i e n t s ~ w i t h ~ R A . ~(a) ~ I n t r a c e l l u l a r ~ C a 2+~ m e a-~}$ surement showing the effect of external application of $100 \mu \mathrm{M}$ PregS in the presence and absence of extracellular Ca2+. (b) As for (a) but the effect of PregS $(100 \mu \mathrm{M})$ and then addition of $20 \mu \mathrm{M} \mathrm{SPH}$. (c) As for (a) but paired experiments on the same 96-well plate where responses were compared after pre-treatment with anti-TRPM3 antibody (TM3E3) or TM3E3 preadsorbed to its antigenic peptide ("+pep."; control group). (a-c) All data points are N $=8$ and representative of $3(\mathrm{n})$ independent experiments. (d) Concentration-dependence of $\mathrm{Ca}^{2+}$-entry evoked by PregS. Mean data are shown for measurement of the peak and sustained responses to PregS (e.g. see (c)); 4 (n) independent experiments. The fitted curves are Hill equations with midpoints at $35.7 \mu \mathrm{M}$ (peak) and $39.5 \mu \mathrm{M}$ (sustained). The shaded area on the left (i) indicates the highest concentrations reported for endogenous PregS [22,23], while the shaded area on the right (ii) indicates the higher concentrations of plasma PregS predicted on oral administration of 100 mg daily to adult humans.

taken orally at high concentrations and remains readily available, yet major adverse effects are not apparent; (iv) Readily tolerated concentrations of pregnenolone are expected to generate sufficient plasma concentrations of pregnenolone sulphate to stimulate TRPM3 and inhibit hyaluronan secretion; (v) the mechanism of action of pregnenolone is distinct from that of dexamethasone and it is expected to lack the unwanted effects of glucocorticoids. Although pregnenolone is the precursor for all steroid hormones, administration of pregnenolone does not appear to elevate concentrations of sex steroids, presumably because of sulphation and rate-limiting steps in steroid hormone synthesis. A reason not to consider pregnenolone as potentially clinically relevant in RA is that the field has moved forward enormously since the studies of the 1950s. Can an endogenous steroid be seri- ously considered at time of major breakthroughs in biological (antibody) drug treatment? We suggest that it may have a valuable role to play but that rigorous clinical trials would be needed first. The potentially low cost of pregnenolone could be attractive to health providers and pregnenolone could confer a useful addition to therapeutic options during flare or during periods of remission after biological therapy.

It was reported that sphingosine and dimethylsphingosine stimulate over-expressed human TRPM3 [8] and we confirmed this observation when transiently expressing the same clone [11]. Another research group suggested that sphingosine is ineffective as a stimulator of TRPM3 and has non-specific effects [10]. We do not know the explanation for the difference but our data on endogenous TRPM3 of FLSs supports the view that 
a
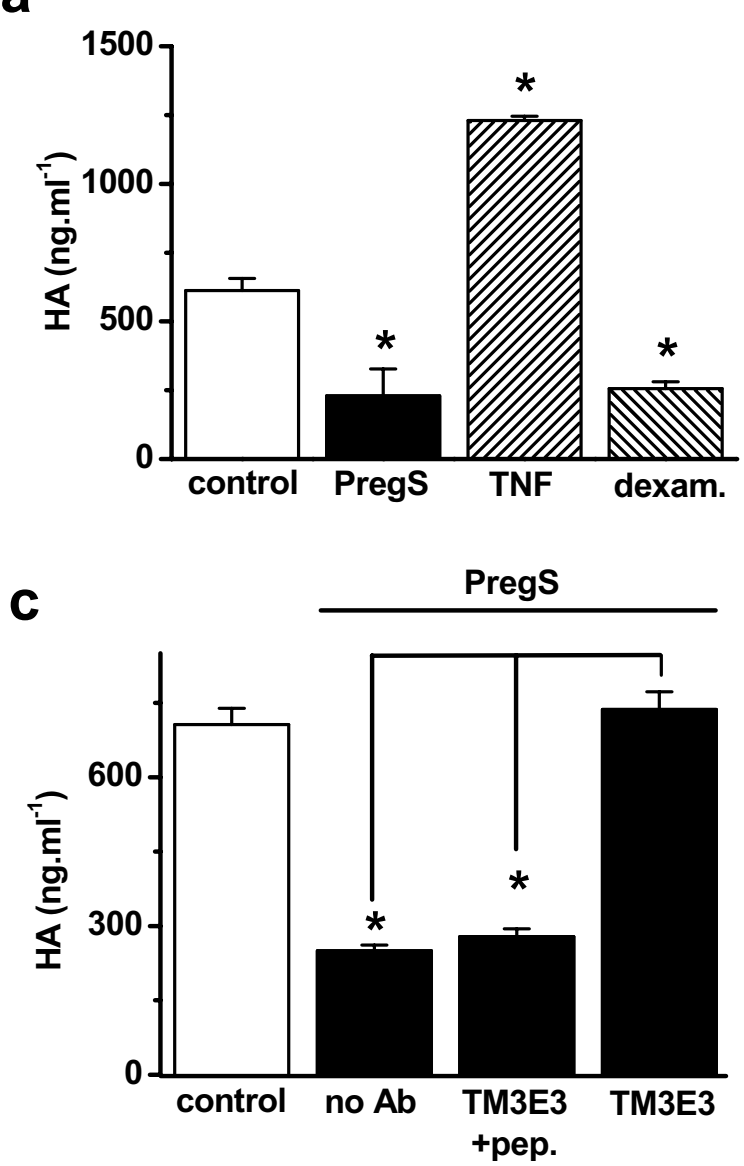

b

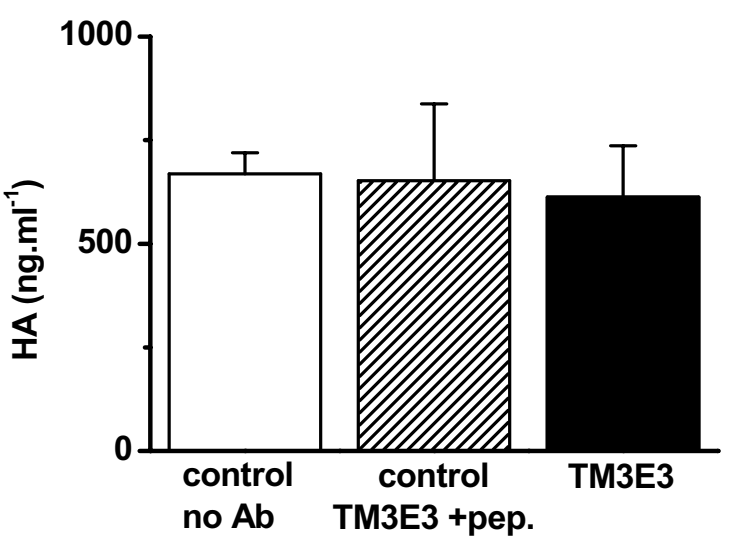

d

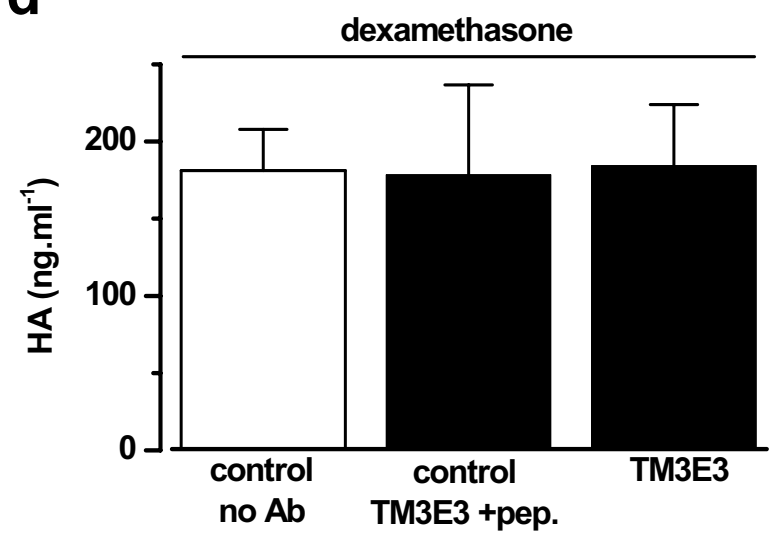

Figure 6 Negative coupling to hyaluronan secretion in primary cultures of FLSs from patients with RA. Data are from measurements of hyaluronan derived from cells of 6 (a-c) or 3 (d) patient samples. (a) Mean effects of $100 \mu \mathrm{M}$ pregnenolone sulphate (PregS), $10 \mathrm{ng} / \mathrm{ml}$ tumor necrosis factor (TNF) and $1 \mathrm{\mu g} / \mathrm{ml}$ dexamethasone; 'control' was the solvent. (b) Mean data showing no effect of anti-TRPM3 antibody (TM3E3) on basal hyaluronan secretion; one control was without TM3E3 (no Ab) and another was from cells pretreated with TM3E3 preadsorbed to its antigenic peptide (TM3E3 + pep.). (c) As for (b) but showing the effect $100 \mu \mathrm{M}$ PregS under the different antibody (Ab) conditions; the control was cells without PregS. (d) Failure of TM3E3 to protect against the inhibitory effect of $1 \mu \mathrm{g} / \mathrm{ml}$ dexamethasone.

sphingosine stimulates TRPM3; nevertheless, we have no strong argument for it as a physiological regulator of TRPM3.

We previously evaluated anti-TRPM3 antibody, TM3E3, against the function of human TRPM3 overexpressed in HEK 293 cells [11]. The antibody had a blocking effect in a variety of assays but it was striking that the effect was only partial $(<50 \%$ inhibition). It was therefore surprising to find such a strong effect in FLS studies. The greater effect may have arisen because the FLS studies involved endogenous TRPM3, with normal expression and degradation mechanisms. In HEK 293 cell over-expression studies, expression is driven at a high rate, conferring rapid replacement of channels at the cell surface and possibly saturation of degradation mechanisms. We suspect that the antibody inhibits channels, at least in part, via a mechanism that requires channel inter- nalization. Therefore, over-expression studies may underestimate the degree of block because new channels replace antibody-bound channels and internalization of bound channels is slow.

\section{Conclusions}

The data suggest expression and function of TRPM3 channels in cells that line the synovium of joints of patients suffering from rheumatoid arthritis. TRPM3 could also be detected in cells of the sub-lining layer and in small blood vessels of the joints, consistent with a recent report of vascular TRPM3 expression [25]. The channels may be stimulated by sphingosine or pregnenolone sulphate but the physiological relevance of these stimulators is uncertain. Instead we discuss arguments for further investigation of pregnenolone as a treatment for RA, acting in part through negative cou- 
pling to hyaluronan and potentially lacking unwanted effects of glucocorticoids. Overall, the data add to an emerging picture of TRP channel function in the synovium and suggest previously unrecognized regulation of hyaluronan secretion by ion channel activity at the plasma membrane.

\section{Additional material}

\section{Additional file 1 Summary of reports on effects of pregnenolone} administration on patients with rheumatoid arthritis.

\section{Abbreviations}

TRP: Transient Receptor Potential; TRPM: Transient Receptor Potential Melastatin; FLS: fibroblast-like synoviocyte; RA: rheumatoid arthritis.

\section{Competing interests}

The authors declare that they have no competing interests.

\section{Authors' contributions}

CC and YM performed experiments and provided intellectual input, JN provided experimental tools and technical input, PS performed experiments, AE and PE provided and characterized tissue samples, and DJB provided the intellectual basis for the project, coordinated the project and wrote the paper. All authors read and approved the final manuscript.

\section{Acknowledgements}

We thank the Wellcome Trust and Physiological Society for research grants. YM was funded by a University PhD Studentship, PS by ORS and University PhD Student Awards, and JN by a BBSRC Collaborative PhD Studentship with AstraZeneca.

\section{Author Details}

${ }^{1}$ Institute of Membrane \& Systems Biology, Faculty of Biological Sciences, University of Leeds, Leeds, LS2 9JT, UK, ${ }^{2}$ Carol Davila University of Medicine \& Pharmacy, Bucharest, Romania and ${ }^{3}$ Academic Section of Musculoskeletal Disease, University of Leeds, Chapel Allerton Hospital, Leeds LS7 4SA, UK

Received: 10 February 2010 Accepted: 4 June 2010

Published: 4 June 2010

\section{References}

1. Nilius B, Owsianik G, Voets T, Peters JA: Transient receptor potential cation channels in disease. Physiol Rev 2007, 87(1):165-217.

2. Venkatachalam K, Montell C: TRP channels. Annu Rev Biochem 2007 , 76:387-417

3. Xu SZ, Sukumar P, Zeng F, Li J, Jairaman A, English A, et al:: TRPC channel activation by extracellular thioredoxin. Nature 2008, 451(7174):69-72.

4. Kochukov MY, McNearney TA, Fu Y, Westlund KN: Thermosensitive TRP ion channels mediate cytosolic calcium response in human synoviocytes. Am J Physio/ Cell Physiol 2006, 291(3):C424-32

5. Itoh Y, Hatano N, Hayashi H, Onozaki K, Miyazawa K, Muraki K: An environmental sensor, TRPV4 is a novel regulator of intracellular $\mathrm{Ca}^{2+}$ in human synoviocytes. Am J Physiol Cell Physiol 2009, 297(5):C1082-90.

6. Lee N, Chen J, Sun L, Wu S, Gray KR, Rich A, Huang M, Lin JH, Feder JN, Janovitz EB, Levesque PC, Blanar MA: Expression and characterization of human transient receptor potential melastatin 3 (hTRPM3). J Biol Chem 2003, 278(23):20890-7.

7. Grimm C, Kraft R, Sauerbruch S, Schultz G, Harteneck C: Molecular and functional characterization of the melastatin-related cation channel TRPM3. J Biol Chem 2003, 278(24):21493-501.

8. Grimm C, Kraft R, Schultz G, Harteneck C: Activation of the melastatinrelated cation channel TRPM3 by D-erythro-sphingosine. Mol Pharmacol 2005, 67(3):798-805.

9. Oberwinkler J, Phillipp SE: Trpm3. Handb Exp Pharmacol 2007:253-67

10. Wagner TF, Loch S, Lambert S, Straub I, Mannebach S, Mathar I, Düfer M, Lis A, Flockerzi V, Philipp SE, Oberwinkler J: Transient receptor potential
M3 channels are ionotropic steroid receptors in pancreatic beta cells. Nat Cell Biol 2008, 10(12):1421-30.

11. Naylor J, Milligan CJ, Zeng F, Jones C, Beech DJ: Production of a specific extracellular inhibitor of TRPM3 channels. Br J Pharmacol 2008 , 155(4):567-73.

12. Sedlácek M, Korínek M, Petrovic M, Cais O, Adamusová E, Chodounská H, Vyklický L: Neurosteroid modulation of ionotropic glutamate receptors and excitatory synaptic transmission. Physiol Res 2008, 57(Suppl 3):S49-57.

13. Zheng P: Neuroactive steroid regulation of neurotransmitter release in the CNS: action, mechanism and possible significance. Prog Neurobiol 2009, 89(2):134-52.

14. Imamura F, Aono H, Hasunuma T, Sumida T, Tateishi H, Maruo S, Nishioka K: Monoclonal expansion of synoviocytes in rheumatoid arthritis. Arthritis Rheum 1998, 41(11):1979-86.

15. Ohshima S, Mima T, Sasai M, Nishioka K, Shimizu M, Murata N, Yoshikawa H, Nakanishi K, Suemura M, McCloskey RV, Kishimoto T, Saeki Y: Tumour necrosis factor alpha (TNF-alpha) interferes with Fas-mediated apoptotic cell death on rheumatoid arthritis (RA) synovial cells: a possible mechanism of rheumatoid synovial hyperplasia and a clinical benefit of anti-TNF-alpha therapy for RA. Cytokine 2000, 12(3):281-8.

16. Stanczyk J, Ospelt C, Gay RE, Gay S: Synovial cell activation. Curr Opin Rheumatol 2006, 18(3):262-7.

17. Stuhlmeier KM: Aspects of the biology of hyaluronan, a largely neglected but extremely versatile molecule. Wien Med Wochenschr 2006, 156(21-22):563-8

18. Bot PT, Hoefer IE, Piek JJ, Pasterkamp G: Hyaluronic acid: targeting immune modulatory components of the extracellular matrix in atherosclerosis. Curr Med Chem 2008, 15(8):786-91.

19. Voelcker V, Gebhardt C, Averbeck M, Saalbach A, Wolf V, Weih F, Sleeman $J$, Anderegg $U$, Simon J: Hyaluronan fragments induce cytokine and metalloprotease upregulation in human melanoma cells in part by signalling via TLR4. Exp Dermato/ 2008, 17(2):100-7.

20. Georgescu HI, Mendelow D, Evans CH: HIG-82: an established cell line from rabbit periarticular soft tissue, which retains the "activatable" phenotype. In Vitro Cell Dev Biol 1988, 24(10):1015-22.

21. Watanabe H, Davis JB, Smart D, Jerman JC, Smith GD, Hayes P, Vriens J, Cairns W, Wissenbach U, Prenen J, Flockerzi V, Droogmans G, Benham CD, Nilius B: Activation of TRPV4 channels (hVRL-2/mTRP12) by phorbol derivatives. J Biol Chem 2002, 277(16):13569-77.

22. Vogl D, Falk W, Dorner M, Scholmerich J, Straub RH: Serum levels of pregnenolone and 17-hydroxypregnenolone in patients with rheumatoid arthritis and systemic lupus erythematosus: relation to other adrenal hormones. J Rheumatol 2003, 30(2):269-75.

23. Tagawa N, Tamanaka J, Fujinami A, Kobayashi Y, Takano T, Fukata S, Kuma $\mathrm{K}$, Tada H, Amino N: Serum dehydroepiandrosterone, dehydroepiandrosterone sulfate, and pregnenolone sulfate concentrations in patients with hyperthyroidism and hypothyroidism. Clin Chem 2000, 46(4):523-8.

24. Straub RH, Paimela L, Peltomaa R, Scholmerich J, Leirisalo-Repo M: Inadequately low serum levels of steroid hormones in relation to interleukin- 6 and tumor necrosis factor in untreated patients with early rheumatoid arthritis and reactive arthritis. Arthritis Rheum 2002, 46(3):654-62.

25. Naylor J, Li J, Milligan CJ, Zeng F, Sukumar P, Hou B, Sedo A, Yuldasheva N, Majeed Y, Beri D, Jiang S, Seymour VA, McKeown L, Kumar B, Harteneck C, O'Regan D, Wheatcroft SB, Kearney MT, Jones C, Porter KE, Beech DJ: Pregnenolone sulphate- and cholesterol-regulated TRPM3 channels coupled to vascular smooth muscle secretion and contraction. Circ Res 2010, 106(9):1507-15.

\section{Pre-publication history}

The pre-publication history for this paper can be accessed here: http://www.biomedcentral.com/1471-2474/11/111/prepub

\section{doi: 10.1186/1471-2474-11-11}

Cite this article as: Ciurtin et al., TRPM3 channel stimulated by pregnenolone sulphate in synovial fibroblasts and negatively coupled to hyaluronan BMC Musculoskeletal Disorders 2010, 11:111 